\title{
The Role of Metformin in patients with Primary Hypothyroidism
}

Khalid Ibrahim Al-Lehibi*, ,Marwah Isam Abdulrahman **, ,Anmar Alharganee ***

\section{ABSTRACT}

Background: Insulin resistance is present in $50 \%$ or more of patients with primary hypothyroidism. Metformin can decrease TSH levels in these patients by a complex matter, this can be of great help in clinical practice.

Objective: This study was designed to evaluate the effect of metformin in reducing TSH levels in patients with primary hypothyroidism.

Methods: Hundred patients with primary hypothyroidism, 82 females, 18 males were included in this study, everyone was followed up for two months after adding metformin 850 mg twice daily in addition to thyroxin.

Results: 36 patients $(36 \%)$ have a normal baseline TSH and no change after 2 months, 64 patients $(64 \%)$ have a change in TSH either a decrease(49 patients ,79.56\%) or an increase (15 patients , $23.44 \%$ ).

Conclusion: Metformin therapy is highly effective in reducing TSH levels in patients with primary hypothyroidism.

Keywords: Primary hypothyroidism, insulin resistance, metformin.

\section{Corresponding Address:}

*Consultant Physician and Endocrinologist, FRCP-Edin, CABM.

Specialized Center for Endocrinology and Diabetes, Baghdad.

GP Nuclear Medicine, Specialized Center for Endocrinology and Diabetes, Baghdad.

Senior Medical Oncologist, MD, UK, Baghdad

Teaching Hospital.

Received at 9/5/2018

Accepted at 17/2/2019

\section{INTRODUCTION}

Insulin resistance (IR) for several decades was known, and till now, to be linked to type 2 diabetes and later on to metabolic syndrome as a whole.

It is said to be due to impaired biological and physiological responses to insulin in the target tissues. It is a strong independent risk factor for type 2 diabetes with all its sequeles ${ }^{(1,2) \text {. }}$

Several years ago an association between IR and primary hypothyroidism was found in some studies and IR was present in $57.2 \%$ in one of these studies, compared to $5.8 \%$ in healthy individuals, without any detectable endocrine problem ${ }^{(3)}$.

In another study carbimazole was given to experimental rats to induce hypothyroidism, in which IR started to rise when hypothyroidism was evident which was associated with a rise in the levels of some inflammatory markers, such as interleukin 6 (IL-6), tumor necrosis factor alpha(TNF-alpha) and others ${ }^{(4)}$.

Also a a positive correlation between TSH and HOMA-IR score was found in patients with primary hypothyroidism ${ }^{(5-8)}$.

Some other studies had shown that IR occurs in hypothyroid patients due to defects in the ability of insulin to increase the glucose utilization in the peripheral tissues, this could justify the increased risk of IR associated disorders, like cardiovascular disease ${ }^{(9)}$.

The last mentioned problem was found to be associated with altered endothelial function, even in hypothyroid patients who were rendered euthyroid with thyroxin ${ }^{(10)}$. These cardiovascular problems were found to increase even in patients with subclinical hypothyroidism ${ }^{(11,12) .}$

Hypothyroidism is said to be a risk factor for the development of type 2 diabetes ,stressing the role of IR in these patients (13-15).

A question could be logically asked, depending on these information, is it possible to reduce TSH levels in patients with primary hypothyroidism by reducing IR with metformin?.

From time to time endocrinologists are faced with hypothyroid patients who require high doses of thyroxin to reduce their TSH levels, for e.g. $300 \mathrm{mcg}, 400$ mcg or even more. However, their TSH levels still remain high.

From this aspect, we performed our study using metformin, hoping that by reducing IR (may be by another mechanism )we could reduce TSH levels in these patients. 


\section{METHODS}

This interventional, prospective study was performed in the Specialized Center for Endocrinology and Diabetes, Baghdad from May till November 2017. It included 100 patients with primary hypothyroidism, 82 females and 18 males, all were on thyroxin therapy.

Patients consent was taken from each one. None of them has any evident other endocrine problem. Initial $\mathrm{T} 4$ and $\mathrm{TSH}$ were measured for each patient and repeated after adding metformin $850 \mathrm{mg}$ twice daily for two months. Five milliliters of blood were aspirated from each patient for estimation of T4 and TSH, initially and after 2 months, and sent to the Lab. for analysis, in which the COBAS method was used.

Thyroxin dosage was kept the same during the study period. The lab. normal reference range for TSH was 0.25-5 $\mathrm{miu} / \mathrm{ml}$.

Measurement of height and weight was done to all patients at the start and weight measurement was repeated after two months of metformin therapy.

\section{RESULTS}

Table (1) shows the demographic data in addition to TSH levels pre and postmetformin therapy, also the weight initially, and after 2 months, there was a significant change in TSH and weight after 2 months $(\mathrm{P}<0.05)$.

Figure (1) shows the mean TSH before and after metformin for the whole 100 patients,TSH1 for baseline TSH and TSH2 for TSH level after 2 months.

Mean TSH1 was 4.4 while mean TSH2 was $2.8(\mathrm{p}=0.006)$.

Figure (2)shows the different causes of hypothyroidism in the total number of patients , $70 \%$ auto-immune, $23 \%$ postthyroidectomy , 5\% post-radioactive iodine therapy (post-RAI), and 2\% congenital.
Table (2)shows the TSH status after 2 months of metformin therapy, and as it is shown in the table, $36 \%$ have normal initial TSH and remained normal after 2 months ,64\% showed a change in TSH (decreased in49 patients $=76.56 \%$, increased in 15 patients $=23.44 \%$ ).

Further details are shown in table (3) where 40 patients have high TSH1, that decreased after metformin, 9 patients have normal TSH1 ,that decreased after metformin.

In those 40 patients with high TSH1, table (4) shows the mean TSH as 24.56 $\mathrm{miu} / \mathrm{ml}$, while mean TSH2 was $4.4 \mathrm{miu} / \mathrm{ml}$, with a percent reduction of $65.68 \%(\mathrm{p}<0.05)$.

More details can be found in table (5)where 17 out of 40 showed $>90 \%$ reduction in TSH after metformin \& 23 showed $<90 \%$ reduction.

Table (6) shows that among these 40 patients 17 had a mean percent reduction in TSH of $95.9 \%, 11$ patients showed $64.62 \%$ reduction, while 12 patients showed $23.76 \%$ reduction.

Table (7) shows the details of 9 patients with normal TSH1 that decreased with metformin, 3 patients showed 98.98\% reduction ,6 showed $62.01 \%$ reduction.

Table (8) shows the change in weight in 40 patients with high TSH1 and lower TSH2 after metformin ,with a mean decrease in weight of $2.1 \mathrm{~kg}(3.26 \%$ reduction).

The mean weight reduction in 9 patients with normal TSH1 and reduced TSH2 was $1.75 \mathrm{~kg}$ (2\% reduction)as shown in table (9).

Table (10) shows the mean TSH1(9.8) and TSH2 $(19.28 \mathrm{miu} / \mathrm{ml})$ in those 15 patients who showed an increase in TSH after metformin.

Table (11) shows the mean difference in weight ( $0.4 \mathrm{~kg}$ decrease after 2 months) in this last group.

Table (12) shows the details of 7 patients (7\%) who showed resistance to exogenous thyroxin. 
Table 1: shows the demographic data with the change in TSH and weight before and after metformin therapy in the total 100 patients

\begin{tabular}{|c|c|c|c|c|c|c|}
\hline $\begin{array}{l}\text { Group (people) } \\
\mathrm{N}=100\end{array}$ & MEAN & SD & SE & MEDIAN & RANGE & PERCENTAGE\% \\
\hline $\begin{array}{l}\text { Gender } \\
\text { Women/Men } \\
(\mathrm{N}[\%])\end{array}$ & -------- & --------- & --------- & ---------- & --------- & $82(82 \%) / 18(18 \%)$ \\
\hline Age(year) & 45.28 & 11.8 & 1.176 & 45 & $15-77$ & ------------------------ \\
\hline $\begin{array}{l}\text { Weight (Pre- } \\
\text { treatment)KG }\end{array}$ & 80.4 & 17.0 & 1.69 & 80.5 & $45-130$ & ------------------------ \\
\hline $\begin{array}{l}\text { Weight(Post- } \\
\text { treatment)KG }\end{array}$ & 79.2 & 17.0 & 1.689 & 79 & $45-130$ & ------------------------ \\
\hline $\begin{array}{l}* \text { TSH }(\quad \text { Pre- } \\
\text { treatment }) \mu \mathrm{U} / \mathrm{Ml}\end{array}$ & 12.1 & 16.6 & 1.66 & 4.4 & $0.2-60$ & ------------------------ \\
\hline $\begin{array}{l}{ }^{* T S H}( \\
\text { treatment }) \mu \mathrm{U} / \mathrm{Ml}\end{array}$ & 6.59 & 11.35 & 1.13 & 2.8 & $0.05-60$ & ----------------------- \\
\hline Hypertension & ----------- & ---------- & ---------- & ----------- & ---------- & $28 \%$ \\
\hline
\end{tabular}

$\mathrm{P}<0.05$ using Wilcoxon signed ranks test*

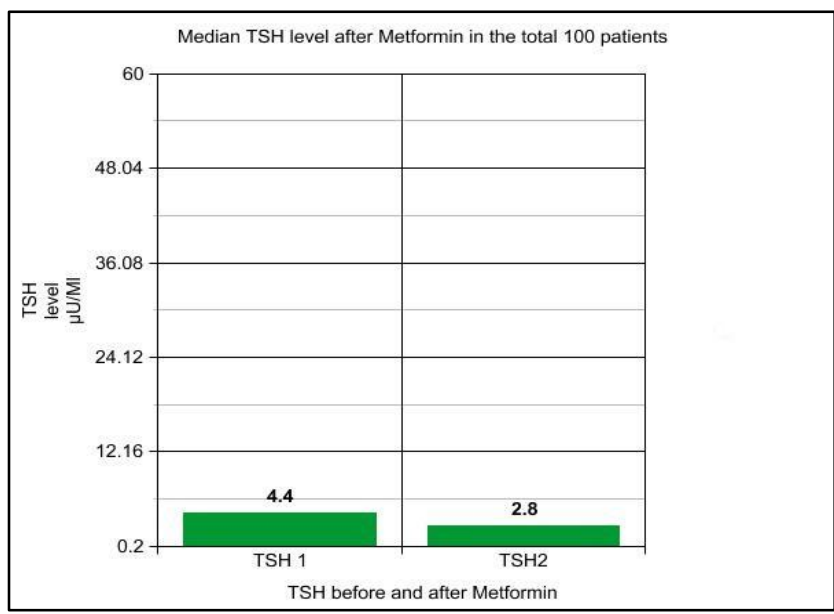

Figure 1:shows median TSH status after metformin in the total 100 patients. TSH 1 indicates initial TSH and TSH 2 indicate level after metformin. ( $\mathrm{P}$ value $=0.006$ using Wilcoxon signed ranks test $)$

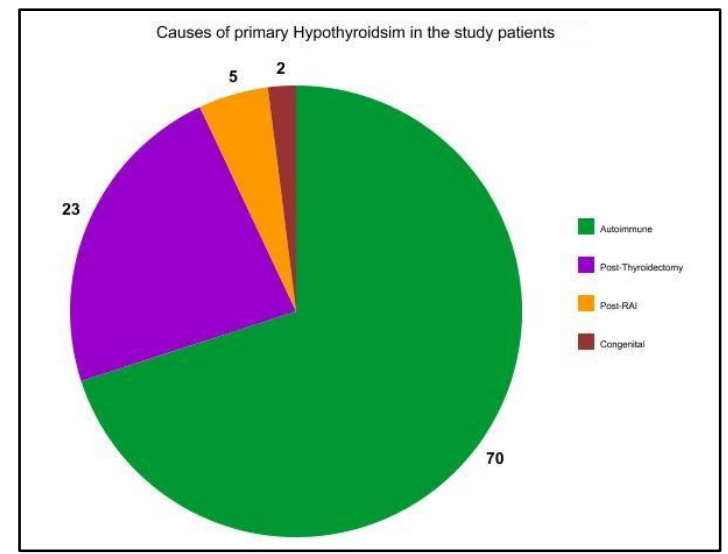


Figure 2:Different causes of primary hypothyroidism in the study patients N=100.

\begin{tabular}{ll}
\hline TSH status after Metformin N=100 & Percentage \\
\hline Normal TSH & $\mathbf{3 6 \%}$ \\
Abnormal TSH & $\mathbf{6 4 \%}$ \\
Decreased & $\mathbf{7 6 . 5 6 \%}$ \\
Increased & $\mathbf{2 3 . 4 4 \%}$ \\
\hline
\end{tabular}

Table2: summarize the TSH status after treatment with Metformin in the total 100 patients.

\begin{tabular}{|l|l|l|}
\hline Number of patients & TSH1 & TSH2 \\
\hline 36 & Normal & Normal \\
\hline 40 & Increased & Decreased \\
\hline 9 & Normal & Decreased \\
\hline 15 & Increased & Increased \\
\hline
\end{tabular}

Table3: shows TSH status after metformin in the total 100 patients. TSH1 indicates initial TSH, TSH 2 indicates TSH level after therapy with metformin.

\begin{tabular}{|l|l|l|l|}
\hline Number of patients & Mean TSH 1 & Mean TSH 2 & $\begin{array}{l}\text { Mean percent } \\
\text { decrease }\end{array}$ \\
\hline 40 & 24.56 & 4.4 & 65.68 \\
\hline
\end{tabular}

Table 4:shows mean TSH before and after metforminP $<0.05$ using Wilcoxon signed ranks test.

\begin{tabular}{|l|l|}
\hline Number of patients & \% of decrease \\
\hline 17 & More than $90 \%$ \\
\hline 23 & Less \\
\hline
\end{tabular}

Table 5: shows the percent TSH decrease after 2 months of metformin therapy in 40 patients with high initial TSH.

\begin{tabular}{|l|l|l|l|l|}
\hline \% of reduction & $\begin{array}{l}\text { Mean \% of } \\
\text { reduction }\end{array}$ & $\begin{array}{l}\text { Number of } \\
\text { patients }\end{array}$ & Mean TSH1 & Mean TSH2 \\
\hline More than 90 & 95.9 & 17 & 35.3 & 1.24 \\
\hline $50-90$ & 64.62 & 11 & 22 & 7.28 \\
\hline Less than 50 & 23.76 & 12 & 8.4 & 6.25 \\
\hline
\end{tabular}

Table 6: TSH status after metformin and percentage of reduction.

\begin{tabular}{|l|l|l|l|l|}
\hline \% of reduction & $\begin{array}{l}\text { Mean \% of } \\
\text { reduction }\end{array}$ & $\begin{array}{l}\text { Number of } \\
\text { patients }\end{array}$ & Mean TSH1 & Mean TSH2 \\
\hline Less than 90 & 98.98 & 3 & 3.23 & 0.067 \\
\hline $50-90$ & 62.01 & 6 & 1.733 & 0.633 \\
\hline
\end{tabular}

Table 7: shows the details of 9 patients with normal TSH1 and $\geq 50 \%$ reduction in TSH after metformin therapy.

\begin{tabular}{|l|l|l|l|l|l|}
\hline $\begin{array}{l}\text { Weight } \\
\text { status }\end{array}$ & $\begin{array}{l}\text { Number of } \\
\text { patients }\end{array}$ & Mean W1 & Mean W2 & $\begin{array}{l}\text { Mean } \\
\text { reduction }\end{array}$ & $\begin{array}{l}\text { \% } \\
\text { reduction }\end{array}$ \\
\hline decreased & 23 & 78.9 & 76.3 & 2.1 & 3.26 \\
\hline No change & 12 & --------- & --------- & ---------- & --------- \\
\hline increased & 5 & 83.6 & 88.1 & 2.5 & 2.91 \\
\hline
\end{tabular}


Table 8: shows the weight status in 40 patients with high initial TSH who their TSH level decreased after metformin. (W 1 =initial weight, W 2= weight after metformin).

\begin{tabular}{|l|l|l|l|l|l|}
\hline $\begin{array}{l}\text { Weight } \\
\text { status }\end{array}$ & $\begin{array}{l}\text { Number of } \\
\text { patients }\end{array}$ & Mean W1 & Mean W2 & $\begin{array}{l}\text { Mean } \\
\text { change }\end{array}$ & $\begin{array}{l}\text { \% of } \\
\text { reduction }\end{array}$ \\
\hline decreased & 4 & 81.5 & 79.75 & 1.75 & 2 \\
\hline No change & 3 & -------- & -------- & --------- & -------- \\
\hline increased & 2 & 58.5 & 59.25 & 0.75 & 1.34 \\
\hline
\end{tabular}

Table 9: shows the weight status in patients with TSH2 decrease after metformin for a normal TSH1. (W 1 =initial weight, W 2= weight after metformin).

\begin{tabular}{|l|l|}
\hline TSH 1 & TSH 2 \\
\hline 9.8 & 19.28 \\
\hline
\end{tabular}

Table10: shows the TSH status after metformin in 15 patients with increase in the TSH after 2 months.

\begin{tabular}{|l|l|l|}
\hline Mean W1 & Mean W2 & Mean change \\
\hline 87.9 & 87.5 & 0.4 \\
\hline
\end{tabular}

Table 11: shows the weight status in 15 patients with increase in the TSH after 2 months.(W 1 =initial weight, $\mathrm{W} 2=$ weight after metformin).

\begin{tabular}{|l|l|l|}
\hline Thyroxin dose $(\boldsymbol{\mu g})$ & Weight $(\mathbf{K g})$ & Thyroxin dose $(\boldsymbol{\mu g} / \mathbf{K g} / \mathbf{d a y})$ \\
\hline 200 & 55 & 3.6 \\
\hline 150 & 65 & 2.3 \\
\hline 300 & 68 & 6.25 \\
\hline 150 & 63 & 2.38 \\
\hline 200 & 85 & 2.35 \\
\hline 150 & 45 & 3.34 \\
\hline 200 & 90 & 2.2 \\
\hline
\end{tabular}

Table 12: shows the dosage of thyroxin $/ \mathrm{kg} /$ day needed to normalize TSH.

\section{DISCUSSION}

From this study we can see the TSHlowering effect of metformin in patients with primary hypothyroidism. Out of 100 patients who were included in this study, 36 patients $(36 \%)$ had a normal initial TSH and showed no change with metformin therapy, while 64 patients (64\%) showed a change in TSH, either a decrease (49 patients, $76.56 \%$ )or an increase (15 patients, $23.44 \%$ ). We believe that, the last group of patients either did not take metformin, or thyroxin, or both , or there might be another unknown mechanism to explain such a rise in TSH as it will be discussed later.

In the whole 100 patients, mean TSH1(initial TSH) was 4.4, mean TSH2 (TSH after 2 months of metformin therapy) was $2.8(\mathrm{P}=0.006)$ as shown in figure (1).

In 40 patients with high TSH1 (mean 24.56), there was a significant reduction in the mean TSH2 (4.4) after metformin $(\mathrm{P}<0.05)$ as shown in table (4).

The TSH lowering effect of metformin cannot just be explained in the basis that it reduces IR, because we have noticed a number of patients with primary hypothyroidism who tried to reduce their weight by dieting and exercise, yet their TSH was not changed . while we know that these measures reduce IR ,this gives an idea that metformin ,by reducing IR, it also stimulates another pathway which helps to strengthen the action of exogenously given thyroxin. This is probably by increasing its action on the receptors in target tissues and in the pituitary itself. This is our explanation , 
otherwise, we did not come across an explanation in the literature.

A number of studies had showed the TSHlowering effect of metformin in patients with primary hypothyroidism who were diabetic and were already on metformin therapy ${ }^{(16,17) \text {. }}$

In one of the studies, there was a $55 \%$ reduction in TSH after metformin ( JeanPascal F) ${ }^{(18) .}$

In some studies, a hypothesis was given to explain the mode of action of metformin in hypothyroid patients saying that it involves the action of metformin on 5AMP activated protein kinase (AMPK), and in the liver, metformin suppresses gluconeogenesis by activating AMPK $(19,20)$.

In our study we found an evident reduction in weight in those patients who showed a reduction in $\mathrm{TSH}$ (mean reduction was $2-1 \mathrm{~kg}(3,26 \%)$ in 23 patients out of 40 with high mean TSH1.

This cannot be related solely to metformin ,as it is weight neutral ,but mostly because it enhances the effect of exogenous thyroxin leading to an increased metabolic rate.

Those 15 patients who had an increase in TSH after metformin showed a minimal mean change in weight $(0.4 \mathrm{~kg})$.

Primary hypothyroidism is said to be refractory to exogenous thyroxin when there is a biochemical or clinical evidence of hypothyroidism i.e. serum TSH above the normal range following a 6-weeks interval after the dose was last increased and/or unresolved symptoms of hypothyroidism despite increasing the dose of thyroxin beyond 1.9 microgram / $\mathrm{kg} /$ day ( 21 ).

In our study , 7 patients ( $7 \%$ ) required > $1.9 \mathrm{mic} . / \mathrm{kg} /$ day to normalize their TSH levels, as it is shown in table 12. This is much lower than the results obtained by Vaisman, in Brazil, who found that resistance to exogenous thyroxin was present in $28 \%$ out of 2292 patients ( 22 ). This difference is most probably because he studied a larger number of patients than we did.

This resistance is said to be due to either patient non-compliance, or the presence of mal-absorption or other causes(23).This can applied to those patients who showed an increase in TSH after 2 months of metformin therapy.

\section{CONCLUSION}

In this study there was a significant reduction in TSH in patients with primary hypothyroidism after 2 months of metformin therapy, there was also an evident reduction in weight, mostly due to the enhancing effect of metformin on exogenous thyroxin therapy. This effect of metformin can solve most of the problems associated with the need for high doses of thyroxin in some patients with primary hypothyroidism who seem to be resistant to the action of thyroxin. We have to declare that this effect of metformin should be observed carefully in patients with cardiovascular problems, because metformin might lead to a reduction of TSH below the acceptable levels leading to tachycardia and dysrrhythmia that might precipitate cardiovascular events in susceptible patients.

\section{REFRENCES}

1. Govindarajan G,et al. What is insulin resistance?. Heart Metab.2006; 30:30-34.

2. Badri NW.et al. Insulin Resistance improves more in women than in men in association with a weight loss intervention .J Obes weight Loss Ther 2018, 8:1.

3. Razaq SH, Allehibi K,Alwachi S. Insulin resistance in hypothyroid patients.Baghdad Science J 2010;21:185-195.

4.Razaq 5H,Allehibi K ,Alwachi S. Comparison study for the effect of Interleukin6 and Carbimazole Drug in Rat Thyroid Gland Functions. Iraqi J Science 2013;54:590-600.

5. Razaq SH, Allehibi K,Alwachi S. Evaluation of some inflammatory markers in hypothyroid resistant patients . Baghdad Science J 2014; 11:33-43.

6. Ana $\mathrm{C}$,et al .Beneficial effects of thyroid hormone on adipose inflammation and insulin sensitivity of obese Wistar rats. Physiol Rep 2018; 6:1-11.

7. Raghad A,Alwachi S,Allehibi K.Detection of pre-diabetes in hypothyroid patients. Intern J Adv Res 2013; 1:423-430.

8. Manju C,Madhur G, Suresh C. Correlation between insulin resistance and homocysteine in hypothyroid patients. JKILMSU; 7:75-81. 
9. Eirin M,et al.Studies of insulin resistance in patients with clinical and subclinical hypothyroid. Eur J Endocrinol 2009; 160:785790.

10. Jose-Manuel F , et al. Thyroid function is intrinsically linked to insulin sensitivity and endothelium-dependent vasodilation in healthy euthyroid sufiects J Clin Endocrinol Metab 2006;91:3337-3343.

11. Sapna V ,et al. Study of insulin resistance in subclinical hypothyroidism .Int J Health Sci Res.2014; 9:147-153.

12. Shyam R, Sunita G, Gaurav S. Insulin resistance in subclinical hypothyroidism . Int J Res Med Sci 2015; 6:1420-1425.

13. Marcin G, Joanna G, Roman J. Insulin resistance and thyroid disorders. Endokrynol pol 2014;65:1-5.

14. Abdel-Gayoum AA. The effect of hypothyroidism on insulin sensitivity and their influence on the serum lipid profile and renal function Endocrinol Metab Syndr 2016; 5 :1-5. 15. Naomi G. et al. Hypothyroidism is a risk factor for new-onset diabetes: A Cohort Study . Diabetes Care;38:1657-1664.

16. Cappelli $\mathrm{C}$,et al. Metformin reduces serum TSH concentration in patients with diabetes. Eur J Endocrinol 2012;167:261-5.
17.Carlo C, et al. TSH-lowering effect of metformin in type 2 diabetic patients.Diabetes Care 2009;32:1589-1590.

18-Jean-Pascal F, et al. Metformin and low levels of thyroid-stimulating hormone in patients with type 2 diabetes mellitus .CMAJ2014;10:1503.

19. Carlo C,et al. Thyrotropin levels in diabetic patients on metformin treatment.Eur $\mathrm{J}$ Endocrinol 2012;167:261-265.

20. Roberta L,et al . Effects of treatment with metformin on TSH levels :A meta-analysis of literature studies. J Clin Endocrinol Metab 2014;99:E143-E148.

21. Centanni M, Benvenga S, Sachmech I.Diagnosis and management of treatmentrefractory hypothyroidism : an expert consensus report. J Endocrinol Inves 2017 ; 40 : 1289-1301.

22- Vaisman F, et al.How good is the levothyroxine replacement in primary hypothyroidism patients in Brazil ? .Data of a multi-center study. J Endocrinol Inves 2013 ; $36: 485-488$.

23- Benvenga $\mathrm{S}$, et al. Delayed intestinal absorption of levothyroxine. Thyroid $1995 ; 5$ : 249-253. 